\title{
No Longer Simply a Practice-based Research Network (PBRN): Health Improvement Networks
}

\author{
Robert L. Williams MD, MPH, and Robert L. Rhyne, MD
}

While primary care Practice-based Research Networks are best known for their original, research purpose, evidence accumulating over the last several years is demonstrating broader values of these collaborations. Studies have demonstrated their role in quality improvement and practice change, in continuing professional education, in clinician retention in medically underserved areas, and in facilitating transition of primary care organization. A role in informing and facilitating health policy development is also suggested. Taking into account this more robust potential, we propose a new title, the Health Improvement Network, and a new vision for Practice-based Research Networks. (J Am Board Fam Med 2011;24:485-488.)

"A group of ambulatory practices devoted principally to the primary care of patients, and affliated in their mission to investigate questions related to communitybased practice and to improve the quality of primary care."

So has the Agency for Healthcare Research and Quality defined a Practice-based Research Network (PBRN). ${ }^{1}$ We believe there are compelling reasons to reinterpret this definition to an exciting and more broadly encompassing vision of these networks.

\section{In the Beginning}

With the establishment of ASPN (Ambulatory Sentinel Practice Network) ${ }^{2}$ and of PROS (Pediatric Research in Office Settings network) ${ }^{3}$ in the 1980s, the predominant model for PBRNs in the United States was established as national organizations of clinicians, often in independent private practices, who collaborated on research describing primary care. As these initial PBRNs gained experience and with the establishment of newer, regional PBRNs in the late 1980s into the 1990s, the scope of PBRN research began to include early

This article was externally peer reviewed.

Submitted 28 March 2011; revised 16 May 2011; accepted 23 May 2011.

From the Department of Family and Community Medicine, University of New Mexico, Albuquerque.

Funding: none.

Conflict of interest: none.

Corresponding author: Robert L. Williams, MD, MPH, School of Medicine, University of New Mexico, Albuquerque, NM 87131 (E-mail: rlwilliams@salud.unm.edu). interventional research and more sophisticated research designs. The unifying focus of PBRNs, however, remained on research about and in primary care, and almost all networks were composed principally of private practitioners and academics. (Green and Hickner have provided an excellent history of the development of PBRNs, for those interested in more detail. ${ }^{4}$ )

An important evolution of PBRNs began to take shape around the turn of the century as federal funders, in providing precious infrastructure funding for PBRNs, prioritized networks with clinicians caring for underserved populations. This led to the formation and growth of PBRNs with greater representation by clinicians outside of private practice, such as community health centers and Indian Health Service. Although the major focus continued to be on primary care research and its processes, a subtle change resulted from this expanded inclusion of clinicians in underserved communities. Network clinicians, patients, and community members began to view many health problems seen in primary care, and therefore research on those problems, as being rooted in the community. Research in some PBRNs began to take the form of a partnership between clinicians and their communities, and the reach of that research now included interventions linking primary care and communities. ${ }^{5}$ Communities began to participate in the research process, in some cases even to become partners with the PBRNs and their clinicians, defining research priorities and approaches. ${ }^{6-8}$ 


\section{A Newer Vision}

As important as this transition in PBRN research has been, this may be just the beginning. Emerging evidence and the evolving health care delivery environment have revealed exciting new potential for PBRNs apart from their traditional roles in research.

\section{Quality Improvement/Clinical Practice Change}

Ornstein, Mold, and colleagues have led the way in showing how the PBRN can be an important tool for quality improvement in primary care while also advancing research goals. ${ }^{9-14}$ Other PBRNs have adopted this focus on quality improvement as well. ${ }^{15}$ Elsewhere in the Fournal, we present evidence suggesting that participation in PBRN studies can lead to long-term change in clinical practice behavior. ${ }^{16}$ Although this work is preliminary, it raises intriguing questions about the potential for networks to create lasting change in the primary care clinical encounter, when they focus their research on topics of interest to the clinician and when they provide useful and feasible clinical tools to the clinician. If confirmed by further study, this observation suggests that PBRNs can be a means to catalyze adoption of new clinical practices.

\section{Organization of Clinical Practice}

At the same time, a number of PBRNs have tested and facilitated the implementation of health systems changes, such as adoption of new information technology processes in member practices and the organization of practices to facilitate delivery of care. This expanded application of PBRNs is clearly an area of interest for a number of stakeholders and funders, as exemplified by the interest of the National Institutes of Health's Clinical and Translational Science Award program in PBRNs. Clinical and Translational Science centers are interested in PBRNs not only for their role in conduct of research in real-world settings but also for their potential to speed the translation of clinical research findings into everyday practice. ${ }^{17}$ The Agency for Healthcare Research and Quality's recent call for applications for statewide demonstration-type projects aimed at catalyzing the transition of practices to patient-centered medical homes suggests the potential for PBRNs in supporting health systems change at the practice level. ${ }^{18}$ Participation in PBRN studies has been shown to benefit prac- tices beyond the goals of the specific study being conducted. ${ }^{19}$

\section{Continuing Medical Education and Clinical Training}

An often underappreciated attribute of PBRNs is their educational value for participating clinicians. Continuing medical education (CME) has been shown to be incentive for participating in PPRN studies. ${ }^{20}$ With the philosophy that PBRN members learn from their participation in studies, our regional network offers $\mathrm{CME}$ credit for participating in studies, for reviewing results of the studies, for attending presentations on the application of those results, and for attending meetings which assist in planning future studies. Additional CME is offered if any member formally participates in educational programs related to the study topic. ${ }^{21,22}$ We are currently exploring new ways to provide education on translating research findings into practice to PBRN members, their clinic staff and their community members.

\section{Clinician Retention in Underserved Communities}

In a recent publication, we presented evidence of an association of PBRN membership to retention of clinicians in medically underserved communities. ${ }^{23}$ PBRN research provides its members intellectual stimulation and a scholarly element to their practices; it provides meaning, a connection to the profession, an opportunity to perform quality improvement, and a feeling of contributing locally relevant knowledge. ${ }^{24,25}$ Earlier research suggested that busy clinicians participate in PBRNs out of interest in having a scholarly element of their practice. ${ }^{26}$ For clinicians in underserved communities, perhaps this scholarly side of practice is important in the balance that leads to decisions to continue in these communities.

\section{Policy Change}

Unpublished experience in our regional PBRN has shown widespread interest among network members in using network research to facilitate local and state policy development to address priority health and health services problems. Our network members have repeatedly articulated an interest in linking their clinical work and their collective PBRN research to policy efforts aimed at tackling the underlying factors driving major health problems. In response, our network has established ongoing relationships and bidirectional educa- 
tion with state legislators, and created a minifellowship in health policy for practicing clinicians. Through this mini-fellowship, clinicians are provided practice coverage and support to develop a policy initiative related to a network clinical priority topic. Two recent fellows focused on local and state policies to facilitate integration of substance use care in primary care.

\section{A Time to Move Creatively}

These brief descriptions show how some PBRNs have begun to move beyond their original purpose to embrace a spectrum of activities related to improving the care of patients and communities. With engagement of these networks in areas of education, quality improvement, policy change, organization of primary care, and even public health practice ${ }^{27}$ the name "PBRN" has come to seem outmoded and restrictive. We propose that a more appropriate term considering this broader scope of mission and activities should be "Health Improvement Network." Although primary care (or public health) research remains central to the rationale for Health Improvement Networks-HINs-it now can be seen as just one element of the potential of these robust primary care clinician collaborations. Expanding the scope of these collaborations expands their potential realm of influence. Viewed from this perspective, we propose that the Agency for Healthcare Research and Quality's definition of a PBRN should be reinterpreted and expanded to define a Health Improvement Network as:

"A group of ambulatory practices devoted principally to the primary care of patients, and affiliated in their mission to improve the health of their patients and communities by investigating questions related to community-based practice and to the quality of primary care, and by supporting clinicians with clinical education, methods to change practice, and opportunities to influence bealth policy."

With the rapidly evolving health care environment and its impacts on primary care, never has there been as much need for and broad, exciting potential for scholarly and active primary care clinician collaborations as there is now. We believe it is time to act on this broader potential, with a new vision of the Health Improvement Network.

We acknowledge and appreciate the insights that each of the participating RIOS Net leaders, clinicians, and staff provided us.

\section{References}

1. Agency for Healthcare Research and Quality. PBRN Primary Care Practice-based Research Networks, Frequently Asked Questions. Available at: http:// pbrn.ahrq.gov/portal/server.pt?cached $=$ true\&mode $=$ $2 \&$ objID $=860 \&$ open $=512$ \#pbrn_name. Accessed on March 26, 2011.

2. Green LA, Wood M, Becker L, et al. The ambulatory sentinel practice network: purpose, methods and policies. J Fam Pract 1984;18:275-80.

3. American Academy of Pediatrics. PROS, Pediatric Research in Office Settings, About PROS. Available at: http://www.aap.org/pros/abtpros.htm. Accessed on March 26, 2011.

4. Green LA, Hickner J. A short history of primary care practice-based research networks: from concept to essential research laboratories. J Am Board Fam Med 2006;19:1-10.

5. Rust G, Cooper LA. How can practice-based research contribute to the elimination of health disparities? J Am Board Fam Med 2007;20:105-14.

6. Westfall JM, Fagnan LF, Handley M, et al. Practicebased research is community engagement. J Am Board Fam Med 2009;22:423-7.

7. Williams RL, Shelley BM, Sussman AL. The marriage of community-based participatory research and practice-based research networks: can it work? A RIOS Net Study. J Am Board Fam Med 2009;22:428-35.

8. Sussman AL, Rivera M. 'Be gentle and be sincere about it': a story about community-based primary care research. Ann Fam Med 2008;6:463-5.

9. Mold JM, Peterson KA. Primary care practice-based research networks: working at the interface between research and quality improvement. Ann Fam Med 2005;3(Suppl 1):S12-20.

10. Aspy CB, Enright M, Halstead L, Mold JW. Improving mammography screening using best practices and practice enhancement assistants: an Oklahoma Physicians Resource/Research Network (OKPRN) study. J Am Board Fam Med 2008;21: 326-33.

11. Nagykaldi Z, Mold JW, Robinson A, et al. Practice facilitators and practice-based research networks. J Am Board Fam Med 2006;19:506-10.

12. Ornstein SM, Jenkins RG. Quality of care for chronic illness in primary care: opportunity for improvement in process and outcome measures. Am J Manag Care 1999;5:621-7.

13. Feifer C, Ornstein SM. Strategies for increasing adherence to clinical guidelines and improving patient outcomes in small primary care practices. Jt Comm J Qual Saf 2004;30:432-41.

14. Feifer C, Nemeth L, Nietert PJ, et al. Different paths to high-quality care: three archetypes of top-performing practice sites. Ann Fam Med 2007;5:233-41.

15. Fox CH, Swanson A, Kahn LS, et al. Improving chronic kidney disease care in primary care practices: 
an upstate New York practice-based research network (UNYNET) study. J Am Board Fam Med 2008;21:522-30.

16. Rhyne R, Sussman AL, Fernald D, et al. Reports of persistent change in the clinical encounter following research participation: a report from PRIME Net. J Am Board Fam Med 2011;24:496-502.

17. Fagnan LJ, Davis M, Deyo RA, et al. Linking practice-based research networks and clinical and translational science awards: new opportunities for community engagement by academic health centers. Acad Med 2010;85:476-83.

18. Agency for Healthcare Research and Quality. RFAHS-11-002: Infrastructure for Maintaining Primary Care Transformation (IMPaCT): support for models of multi-sector, state-level excellence (U18). Available at: http://grants.nih.gov/grants/guide/rfafiles/RFA-HS-11-002.html. Accessed March 26, 2011.

19. Yawn BP, Pace W, Dietrich A, et al. Practice benefit from participating in a practice-based research network study of post-partum depression. J Am Board Fam Med 2010;23:455-64.

20. Bakken S, Lantigua FA, Busacca LV, Bibber JT. Barriers, enablers, and incentives for research participation: a report from the ambulatory care research network (ACRN). J Am Board Fam Med 2009;22: 436-45.

21. Leverence RR, Williams RL, Pace W, et al. Context of clinical care: the case of hepatitis $\mathrm{C}$ in underserved communities: a report from the Primary Care Mul- tiethnic Network (PRIME Net) Consortium. J Am Board Fam Med 2009;22:638-46.

22. Williams RL, McPherson L, Kong A, et al, PRIME Net clinicians. Internet-based training in a practicebased research network consortium: a report from the Primary Care Multiethnic Network (PRIME Net). J Am Board Fam Med 2009;22:446-52.

23. Sinclair-Lian N, Rhyne RL, Alexander SH, Williams RL. Practice-based research network membership is associated with retention of clinicians in underserved communities: a Research Involving Outpatient Settings Network (RIOS Net) study. J Am Board Fam Med 2008;21:353-5.

24. Fagnan LJ, Handley MA, Rollins NR, Mold J. Voices from the left of the dial: reflections of practice-based researchers. J Am Board Fam Med 2010; 23:442-51.

25. Gibson K, Szilagyi P, Swanger CM, et al. Physician perspectives on incentives to participate in practicebased research: a greater Rochester practice-based research network (Gr-PBRN) study. J Am Board Fam Med 2010;23:452-4.

26. Green LA, Niebauer LJ, Miller RS, Lutz LJ. An analysis of reasons for discontinuing participation in a practice-based research network. Fam Med 1991; 23:447-9.

27. Center for Public Health Systems and Services Research. Public Health Practice-based Research Networks. Available at: http://www.publichealthsystems. org/pbrn. Accessed on May 16, 2011. 